\title{
A Novel Bond Anchor for Unidirectional FRP Member: Conceptual Design and Experimental Investigation
}

\author{
Yue Liu $\mathbb{D},{ }^{1,2}$ Qing Wei, ${ }^{1}$ Ze-Yu Wang, ${ }^{1}$ Peng Xiang, ${ }^{3}$ Long-Ji Du, ${ }^{4}$ and Bai-Yong Fu ${ }^{4}$ \\ ${ }^{1}$ The Key Laboratory of Urban Security and Disaster Engineering of Ministry of Education, Beijing University of Technology, \\ 100 Pingleyuan, Beijing, China \\ ${ }^{2}$ Central Research Institute of Building and Construction Co. Ltd. MCC, 33 Xitucheng Road, Beijing, China \\ ${ }^{3}$ Anhui Province Highway \& Port Engineering Co. Ltd., 459 Huangshan Road, Hefei, China \\ ${ }^{4}$ CCCC Highway Bridges National Engineering Research Centre Co. Ltd., 23 Huangshi Road, Beijing, China
}

Correspondence should be addressed to Yue Liu; yliu@bjut.edu.cn

Received 11 June 2021; Revised 6 July 2021; Accepted 13 July 2021; Published 20 July 2021

Academic Editor: Haohui Xin

Copyright (C) 2021 Yue Liu et al. This is an open access article distributed under the Creative Commons Attribution License, which permits unrestricted use, distribution, and reproduction in any medium, provided the original work is properly cited.

\begin{abstract}
Fiber-reinforced polymer (FRP) is an advanced composite material with many advantages including light weight, high strength, and high fatigue and corrosion resistance, which makes unidirectional FRP suitable for tension members, such as cables, prestressing tendons, and tie rods. However, the unidirectional FRP is a typical isotropic material, which is difficult to be anchored and hence unable to give full play to the advantages of FRP. To solve the anchoring problem of unidirectional FRP member, a novel bond anchor, i.e., dissolution-rebond anchor, is proposed in this paper. In this novel anchorage system, the polymer matrix of two ends of the unidirectional FRP member is dissolved by solvent and the fibers in the anchorage length are directly bonded by the binder. Theoretical analysis was performed to illustrate the high anchorage bearing capacity of this dissolution-rebond anchor. Static tensile test was conducted to verify this novel anchor design and compare with traditional bond anchor. Results show that the novel dissolution-rebond anchor is feasible and its anchorage efficiency is significantly higher than the traditional bond anchor.
\end{abstract}

\section{Introduction}

Fiber-reinforced polymer, abbreviated as FRP, is an advanced composite material composed of high-performance fibers as reinforcement and polymer as matrix through various molding processes. Common high-performance fibers include carbon fiber, glass fiber, aramid fiber, and basalt fiber. Commonly used polymers include epoxy resin, unsaturated polyester resin, phenolic resin, and polypropylene resin [1]. FRP has the advantages of light weight, high strength, high fatigue and corrosion resistance, etc., which is suitable to be made into cables or prestressing tendons to bear tension in structures [2]. Using FRP tension members to replace traditional steel members is able to improve the mechanical properties and durability of engineering structures.
FRP cables or prestressed tendons are mainly composed of FRP unidirectional members like pultruded rods and lamellas. The unidirectional FRP is a typical orthotropic material, whose fiber direction is along the axial direction of the member. Consequently, it shows the mechanical properties of the fiber along the axial direction, namely, fiber direction; however, it shows the mechanical properties of the polymer perpendicular to the axial direction, which are significantly lower than that of the fiber direction. In addition, FRP has relatively low shear strength and poor ductility [3]. Therefore, it is extremely difficult to anchor unidirectional FRP members. The commonly used anchoring methods for steel members are not suitable for FRP ones, and many special changes have to be made. Current methods for anchoring unidirectional FRP members can be mainly categorized into two types, namely, mechanical 
clamping and bonding [4]. Freyssinet Ltd. cooperated with other companies developed an anchorage system called modular clamp anchor [5] and successfully used it in the Laroin Footbridge [6]. In this anchorage system, each FRP parallel 7-wire bundle is clamped as a module by the steel wedges. In order to prevent the transversal damage of FRP from directly clamping, every wire is protected by an aluminum sheath [3]. Andrä and Maier [7] proposed a clamp anchor with variable clamping stiffness. The thickness of its clamping plate gradually increased from the back to the front of the anchor, which can effectively reduce the peak stress of FRP member in the anchorage length and improve the anchorage efficiency. Burtscher [8] proposed a composite wedge clamp anchor. The wedge is composed of steel and epoxy resin. The epoxy resin part contacts with FRP, and its thickness gradually decreases from the anchorage front to the anchorage back end. This special design can effectively reduce the peak stress of FRP, prevent its early failure, and improve the anchorage efficiency. In addition, the surface of wedge epoxy resin is serrated rather than smooth, which can effectively increase the friction coefficient. Tokyo Rope Ltd. developed a straight tube bond anchor with highly expansive binder [9]. Using straight tube instead of conical tube is able to reduce the stress peak of FRP cable at the anchorage exit and increase the anchorage efficiency, and the highly expansive binder can generate enough radial pressure to grip the FRP cable. Meier et al. [10] proposed a bond anchor with gradient stiffness, using conical anchor socket and epoxy resin with alumina oxide $\left(\mathrm{Al}_{2} \mathrm{O}_{3}\right)$ particles as the binder. By increasing the density of $\mathrm{Al}_{2} \mathrm{O}_{3}$ particles in the epoxy resin from the anchorage exit to the anchorage back end, the stiffness of the binder increases gradually from the exit to the back end, so that the stress distribution of FRP in anchorage zone is more uniform and the anchorage efficiency is improved. This gradient stiffness bond anchor was successfully used in the first FRP highway cable-stayed bridge of the world and inspired the design of later generations [11]. Lv and Mei [12] designed a special bond anchor for FRP parallel rod cables and used it in the first FRP cable-stayed bridge in China. This bond anchor is called the straight tube and inner cone anchor, because the inner shape of the socket near the anchorage exit is cylindrical while near the back end is conical. In this way, the stress peak of the FRP cable in the anchorage zone can be significantly reduced and the anchorage efficiency can be improved. Schlaich et al. [13] and Schmidt et al. [14] reviewed the existing anchorage systems of FRP members. It can be concluded that most of existing FRP anchors are the imitation of anchors for steel members, without fully considering the material characteristics of FRP. These anchorage systems often have shortcomings such as too long anchorage length, too large volume, and too complex and poor economy.

In view of this, a new type of bond anchor suitable for unidirectional FRP members is proposed in this paper. The polymer matrix at two ends of the FRP member is dissolved by solvent, and the fibers in FRP are directly bonded by the binder, which can greatly increase the bonding surface area and improve the anchorage efficiency. The manufacturing method of the novel anchorage system was firstly introduced, and then the theoretical analysis and experimental verification were carried out.

\section{Manufacturing of the Dissolution- Rebond Anchor}

In order to directly bond the fibers of FRP, it is necessary to firstly dissolve the polymer matrix of the anchorage zone at both ends of the FRP member. After the dissolution is completed, the fiber bundle is inserted into the anchorage socket, and then the binder is injected into it. The entire manufacturing method is a process of dissolving and rebonding.

The detailed manufacturing steps of the dissolutionrebond anchor are listed as follows. It should be noted that the manufacturing process is not only for the single FRP member but also for the FRP member bundle:

Step 1. Select a single unidirectional FRP member or a unidirectional FRP member bundle with no external damage.

Step 2. Cut the unidirectional FRP member or member bundle into the design length by cutting machine.

Step 3. Determine the length of dissolution at both ends according to the design factors, including required anchoring force, the number of fibers in the unidirectional FRP member, the diameter of the fiber, the bond strength between the fiber and the binder, and suitable reduction factor.

Step 4. Put one end of the cut unidirectional FRP member or unidirectional FRP member bundle into the container filled with solvent (see Figures 1 and 2), so that the solvent can dissolve the polymer matrix within the anchorage length determined by step 3, and the FRP member or member bundle is taken out and the fibers are washed in water and dried in air after the polymer is dissolved.

Step 5. After one end is dissolved, the other end of unidirectional FRP member or member bundle is put into the container containing suitable solvent, and the polymer matrix of the other end is dissolved like in step 4.

Step 6. Machining the socket with inner conical cavity, the inner taper is $2 \sim 8$ degrees, and the inner surface of the socket is roughed to increase the friction coefficient.

Step 7. The unidirectional FRP member or member bundle with both ends dissolved are inserted into the socket, and the member bundle needs to be put together and tightened. Then, the unidirectional FRP member or member bundle is centered and fixed, and the binder is injected into the socket guaranteeing all the bare fibers immersed by the binder. This process is depicted in Figure 3.

Step 8. Repeat step 7 to complete the other end's anchor of the unidirectional FRP member or member bundle.

The complete dissolution-rebond anchors of single unidirectional FRP member and unidirectional FRP member bundle are shown in Figures 4 and 5, respectively. 


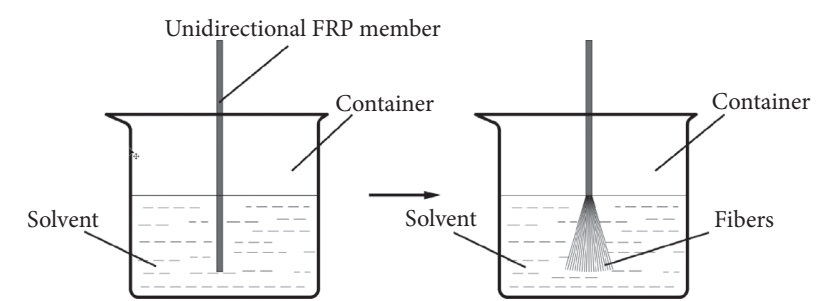

FIGURE 1: Dissolving the end of single unidirectional FRP member.

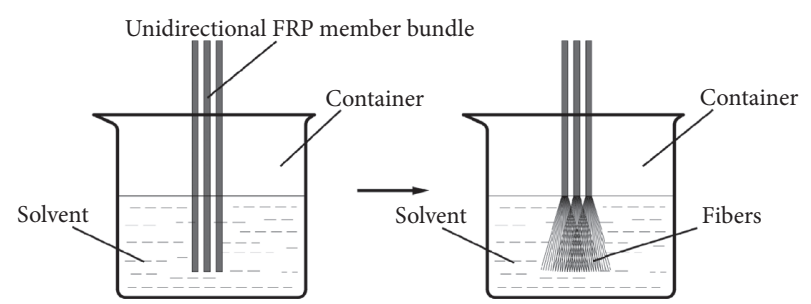

FIgURE 2: Dissolving the end of unidirectional FRP member bundle.

The solvents used to dissolve the polymer matrix at the ends of FRP member can be acid solution, alkali solution, organic solvent, or molten salt. After dissolving, the volume residual rate of the polymer should be less than $5 \%$.

\section{Theoretical Analysis}

The working principle of the dissolution-rebond anchor can be visually explained by comparing the tree and the log. The dissolved and rebonded unidirectional FRP member can be seen as a tree, the binder in the socket can be regarded as the soil, and the fibers dispersing in the binder can be seen as the roots of the tree. Through dissolving the polymer and dispersing the fibers in the binder, this can significantly increase the bonding surface area between the "tree" and the "soil" and hence maximizing the anchoring potential of unidirectional FRP member. As the old saying goes, it is easy to pull a $\log$ out, but hard to pull a tree out, as shown in Figure 6.

The theoretical increase of anchorage bearing capacity of dissolution-rebond anchor for a unidirectional FRP member can be calculated by equations (1)-(3).

Assume the unidirectional FRP member is a circular cross-sectional rod with diameter $D$, the fiber diameter is $D_{f}$, the fiber volume ratio is $V_{f}$, and the anchorage length in the socket is $L$. If the traditional bond anchoring method for the unidirectional FRP member is adopted, that is, bonding the FRP with the binder, the bonding surface area is equal to the surface area of the rod within the anchorage length, which can be expressed as

$$
A_{\text {bond }}=\pi D L
$$

If the novel method proposed in this paper is used, that is, directly bonding the fibers in the unidirectional FRP member with the binder, the new bonding surface area is

$$
A_{\text {bond,new }}=\pi D L\left(\frac{D}{D_{f}}\right) V_{f} \text {. }
$$

From these two equations, one can obtain

$$
\frac{A_{\text {bond,new }}}{A_{\text {bond }}}=\left(\frac{D}{D_{f}}\right) V_{f} \text {. }
$$

Equation (3) indicates that the bonding surface area can be theoretically increased by $\left(D / D_{f}\right) V_{f}$ times through directly bonding the fibers as proposed in this paper, and the anchorage bearing capacity can be theoretically increased by $\left(D / D_{f}\right) V_{f}$ times under the same bonding strength. Because the FRP member diameter $D$ is much greater than the fiber diameter $D_{f}$, the increase is also very large.

Based on a specific application condition, combined with the above theoretical equations, the advantage and feasibility of this new anchoring method can be further illustrated. For example, the diameter of the FRP $\operatorname{rod} D=8 \mathrm{~mm}$, the diameter of the fiber $D_{f}=7 \times 10^{-3} \mathrm{~mm}$, the fiber volume ratio $V_{f}=60 \%$, and the anchorage length $L=100 \mathrm{~mm}$. If the traditional bond anchoring method is adopted, according to equation (1), the bonding surface area $A_{\text {bond }}=\pi D L=2512 \mathrm{~mm}^{2}$. If the new method proposed in this paper is adopted, according to equation (2), it can be obtained that the new bonding surface area $A_{\text {bond,new }}=\pi D L\left(D / D_{f}\right) V_{f}=1722514 \mathrm{~mm}^{2}$. Then, according to equation (3), it can be calculated that the bonding surface area of FRP member is increased by $\left(D / D_{f}\right) V_{f}=686$ times, and the anchorage bearing capacity can be also increased by 686 times. It can be seen that the improvements of bonding surface area and anchorage bearing capacity are very significant.

It should be noted that the above theoretical analysis is just an ideal situation. In the real case, the improvement of the anchorage bearing capacity cannot be as high as the theoretical analysis, because many factors can decrease the actual anchorage bearing capacity, such as the breakage of fibers during manufacturing, voids between the fibers and the binder, and the damage of solvent to the fibers, which are not considered in the theoretical analysis. In order to eliminate the difference between the theoretical value and the experimental value, a reduction coefficient can be used to modify the theoretical analysis results.

\section{Experimental Verification}

Static tensile tests of carbon fiber-reinforced polymer (CFRP) pultruded rods anchored by the dissolution-rebond anchor and the traditional bond anchor were performed to verify the feasibility and advantage of the new anchoring method proposed in this paper. The tests were in accordance with the Chinese code "Anchorage, grip and coupler for prestressing tendons (GB/T 14370-2015)" [15].

4.1. Specimen Preparation. The tested CFRP rod was a plain rod with $500 \mathrm{~mm}$ length and $8 \mathrm{~mm}$ diameter. The carbon fiber was T300 with a diameter of $7 \times 10^{-3} \mathrm{~mm}$ [16], and the polymer matrix used was epoxy resin [17]. Moreover, the 


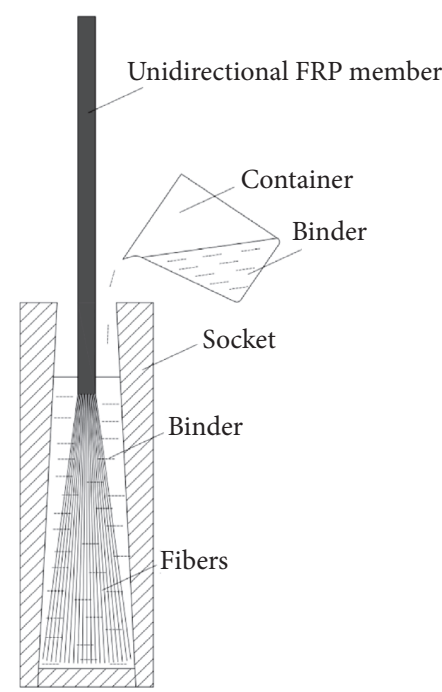

(a)

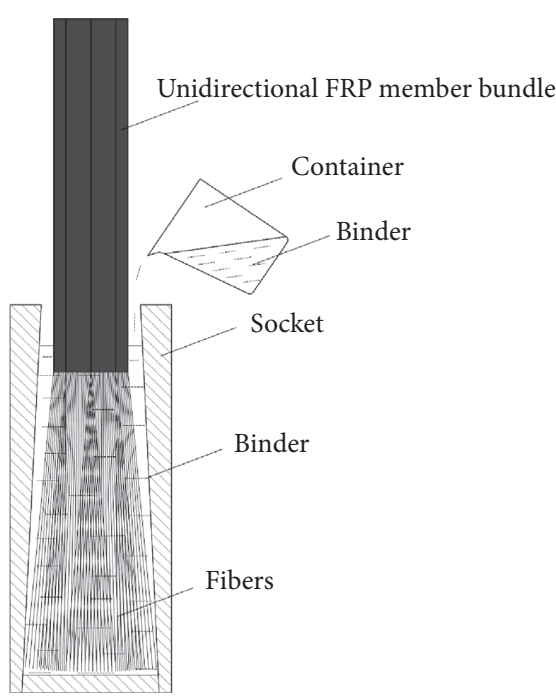

(b)

FIgURE 3: Bonding the fibers of FRP member. (a) Unidirectional FRP member. (b) Unidirectional FRP member bundle.

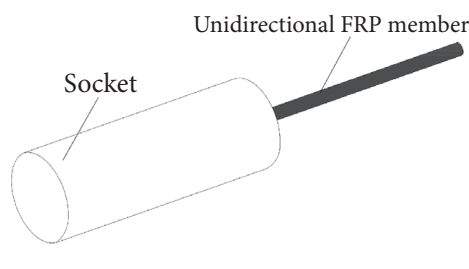

(a)

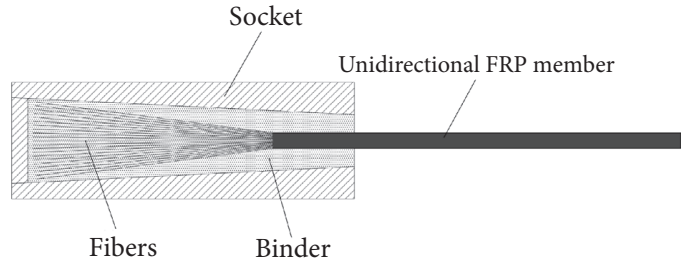

(b)

FIgURE 4: Diagram of dissolution-rebond anchor of a single unidirectional FRP member. (a) Elevation. (b) Profile.

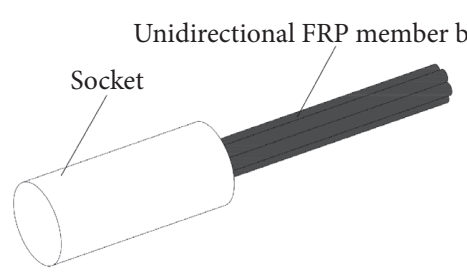

(a)

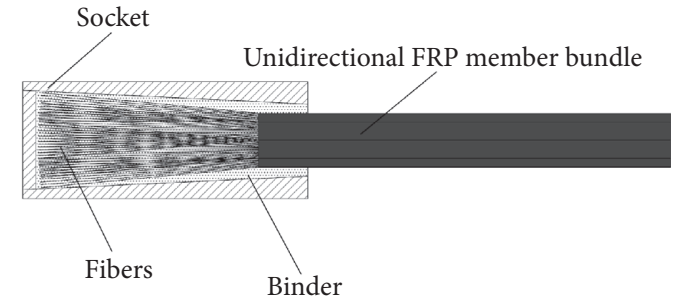

(b)

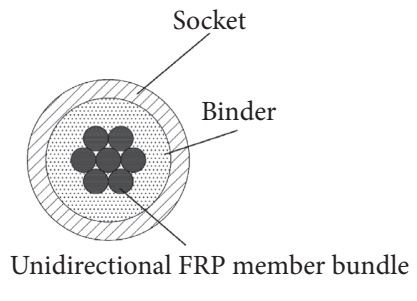

(c)

FIGURE 5: Diagram of dissolution-rebond anchor of a unidirectional FRP member bundle. (a) Elevation. (b) Profile. (c) Cross section.

fiber volume fraction was $60 \%$. Provided by the producer, the guaranteed tensile strength of the CFRP rod was $1800 \mathrm{MPa}$, and its elastic modulus was $140 \mathrm{GPa}$. The CFRP rods are shown in Figure 7.

A single CFRP rod, not rod bundle was anchored. The dissolution-rebond anchor for the CFRP rod was manufactured according to the operation steps introduced in Section 2 of this paper. The solvent used to dissolve the polymer matrix of the ends of the CFRP rod was molten zinc chloride [18]. After dissolving, washing, and drying, the CFRP rods with bare fibers at both ends are shown in Figure 8.
The same binder and socket were adopted for both types of CFRP rods. The binder used was a carbon fiber impregnating adhesive (main component: epoxy resin) with the tensile strength of $20 \mathrm{MPa}$, compressive strength of $70 \mathrm{MPa}$, elongation at break of $3 \sim 7 \%$, and curing time of $50 \sim 70 \mathrm{~min}$ at room temperature [19]. The inner conical socket used is shown in Figures 9 and 10. As can be seen, the total length of the socket was $100 \mathrm{~mm}$, the outer diameter was $36 \mathrm{~mm}$, and the inner diameters of the front and rear ends were $26 \mathrm{~mm}$ and $16 \mathrm{~mm}$, respectively; that is, the taper was $2.9^{\circ}$. The socket material was the $45 \#$ steel with a yield strength of $355 \mathrm{MPa}$ and ultimate strength of $600 \mathrm{MPa}$ [20]. 


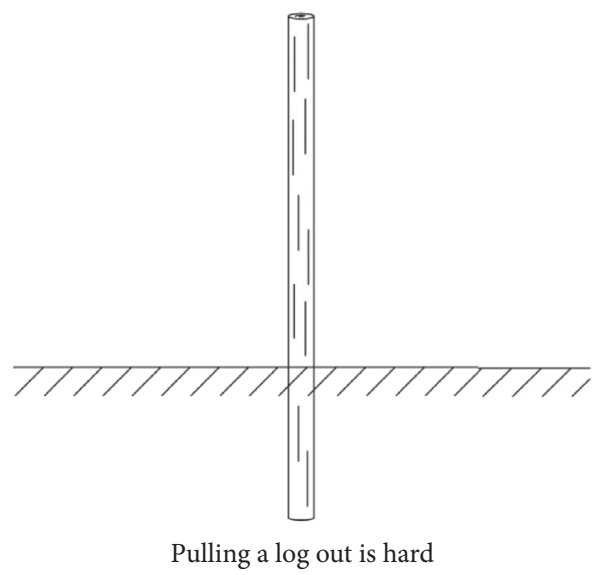

(a)

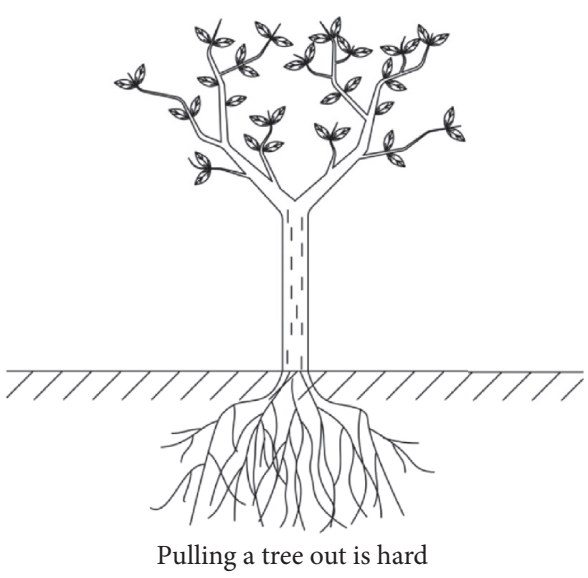

(b)

Figure 6: Visual explanation of working principle of dissolution-rebond anchor.

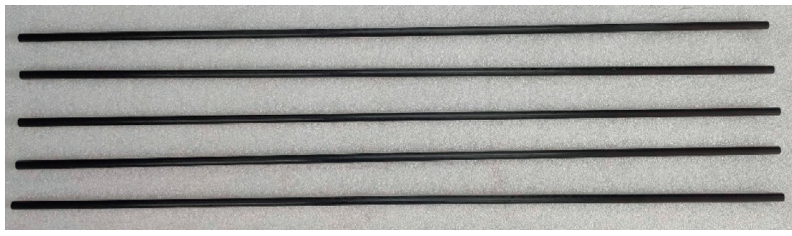

FIGURE 7: CFRP plain rods used.

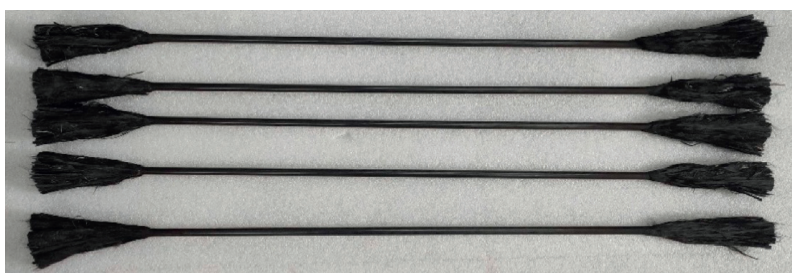

Figure 8: CFRP rods with exposed fibers at both ends.

For connection, the outer surface of the rear part of the socket was machined with threads.

It should be noted that the anchorage length was only $100 \mathrm{~mm}=12.5 \mathrm{D}$, which was considerably smaller than the commonly used anchorage length $20 D \sim 40 D$ for the bond anchor of CFRP plain rods $[21,22]$. The aim was to verify the feasibility of dissolution-rebond anchor with short anchorage length.

After preparing the CFRP rods, sockets, and binder, the specimens with dissolution-rebond anchors or tradition bond anchors could be manufactured. Furthermore, the CFRP rods were wiped clean, and three strain gauges were attached to the middle and two anchor exits of the CFRP rod, respectively. The specimen is shown in Figures 11 and 12.

4.2. Experimental Setup. There were five specimens tested for each type of anchor, which were divided into two groups with different specimen numbers, as listed in Table 1.

An MTS universal testing machine with the maximum pulling force of $1000 \mathrm{kN}$ [23] was used in the experiment. In order to hinge the specimen to the testing machine, ear plates, pin shafts, and Y-shaped forks were manufactured and assembled with the specimen, as shown in Figure 13.

During the installation, it is necessary to prevent the slant and distortion of the specimen. The complete static tensile test setup is shown in Figure 14.

According to the code, the displacement loading method was adopted, and the loading speed was set to $0.01 \mathrm{~mm} / \mathrm{s}$ [15]. During the test, the strains of the specimens were monitored in real time by the strain gauges, the tensile forces were recorded in real time by the testing machine, and all data were transferred to the computer. The failure process and failure mode of the specimens were visually observed.

\subsection{Test Result}

4.3.1. CFRP Rod Anchored by the Dissolution-Rebond Anchor. The stress-strain curves of five specimens are shown in Figure 15. The strain values came from the strain 


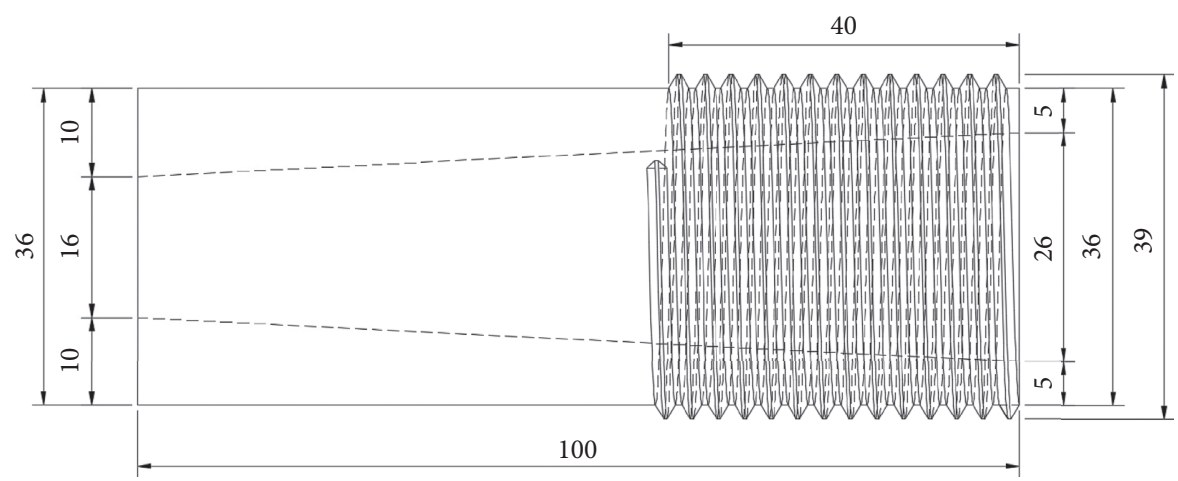

Figure 9: Dimension of anchor socket (unit: $\mathrm{mm}$ ).

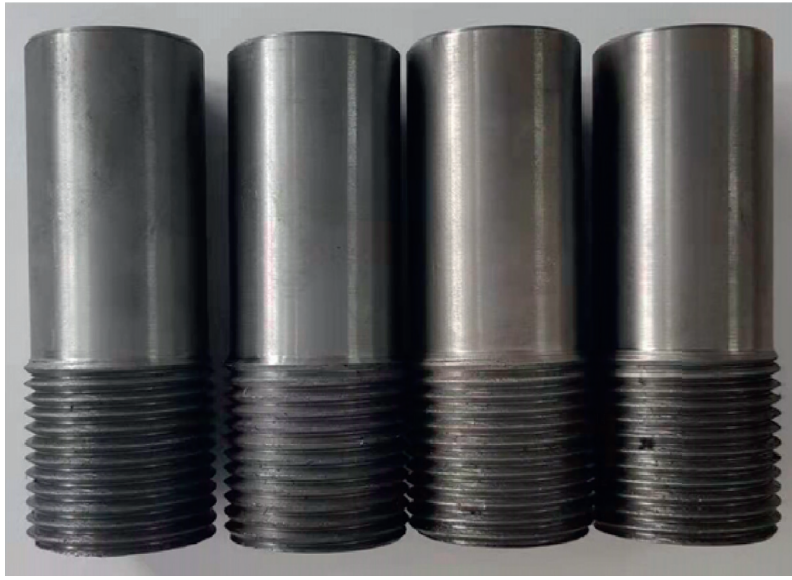

Figure 10: Photo of anchor socket.

gauges, and the stress values were calculated by the tensile force divided by the cross-sectional area (i.e., $50.24 \mathrm{~mm}^{2}$ ). Furthermore, each specimen has three stress-strain curves corresponding to the three strain gauges, and the average curves of five specimens are fitted and compared in Figure 15(f).

As seen from Figure 15, the stress-strain curves of CFRP rod anchored by dissolution-rebond anchor are approximately linear before the peak points, which indicates that the specimens mainly exhibited linear elasticity before failure. After the peak points, there are vertical line segments, which indicates that the stresses dropped very quickly.

The ultimate tensile forces borne by the specimens and the corresponding ultimate tensile stresses are listed in Table 2. As can be seen, the results are relatively uniform, and the average ultimate force and stress are $66.9 \mathrm{kN}$ and 1331.4 MPa, respectively.

During the test, when the tensile load reached approximately $60 \mathrm{kN}$, the specimen of the dissolution-rebond anchor started to make slight sound. Through visual observation, man could not find any slippage between the CFRP rod and the binder. The slight sound might be due to the premature breakage of a small amount of fibers. Then, the load continued to reach the peak value, and the specimen failed with a loud sound. The photos of the specimen after the failure are shown in Figure 16.

As can be seen from Figure 16, the failure mode of the CFRP rod anchored by dissolution-rebond anchor is the typical rupture failure. The failure was due to the breakage of the fibers in the CFRP rod, which occurred at the dissolved and undissolved transition section. After the failure, the dissolved end of the CFRP rod was still in the binder.

According to the code "Anchorage, grip and coupler for prestressing tendons (GB/T 14370-2015)" [15], the anchorage efficiency can be calculated as

$$
\eta_{a}=\frac{F_{\mathrm{Tu}}}{F_{\mathrm{ptk}}},
$$

where $\eta_{a}$ is the anchorage efficiency coefficient, $F_{\mathrm{Tu}}$ is the measured ultimate tensile force from the test, and $F_{\text {ptk }}$ is the nominal ultimate tensile force, which equals the tensile strength of the rod multiplying the cross-sectional area.

The measured ultimate tensile forces $F_{\mathrm{Tu}}$ are listed in Table 2 and the nominal ultimate tensile force $F_{\text {ptk }}=1800 \mathrm{MPa} \times 50.24 \mathrm{~mm}^{2}=90.4 \mathrm{kN}$. The anchorage efficiency coefficients $\eta_{a}$ of the five specimens and the average value are listed in Table 3 . As can be seen, the average 


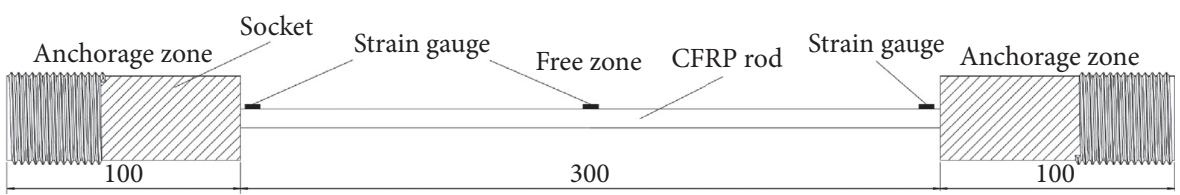

Figure 11: Dimension of the specimen (unit: $\mathrm{mm}$ ).

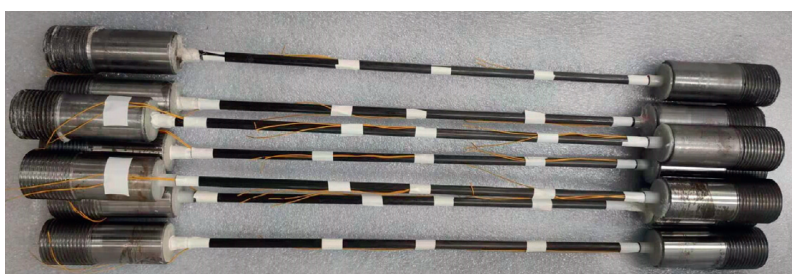

Figure 12: Photo of the specimen.

TABLE 1: Two groups of specimens.

\begin{tabular}{lcccc}
\hline Group name & Specimen number & Anchorage length $(\mathrm{mm})$ & Cross-sectional ${\text { area }\left(\mathrm{mm}^{2}\right)}^{\text {End condition }}$ \\
\hline D & DS1, DS2, DS3, DS4, DS5 & 100 & 50.24 & Dissolved \\
UD & UDS1, UDS2, UDS3, UDS4, UDS5 & 100 & 50.24 & Undissolved \\
\hline
\end{tabular}

DS: dissolved specimen and UDS: undissolved specimen.

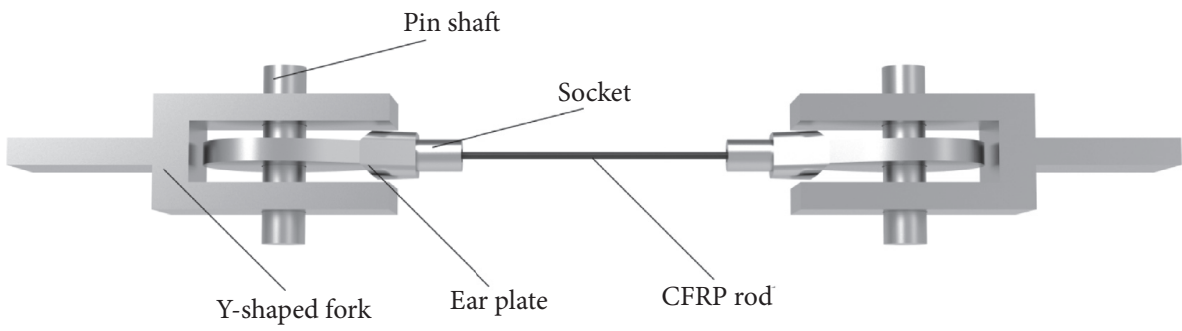

FIGURE 13: Specimen assembled with connection toolings.

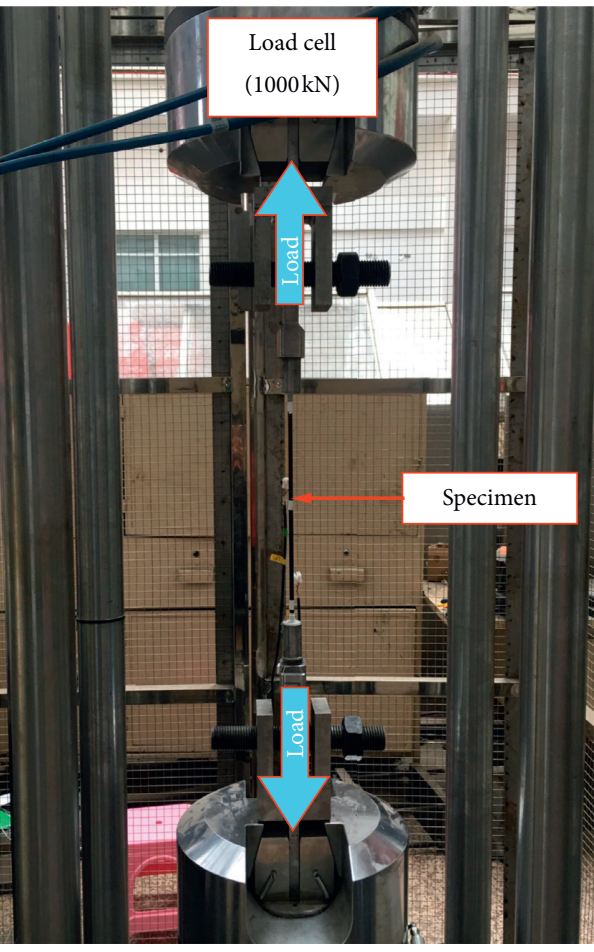

(a)

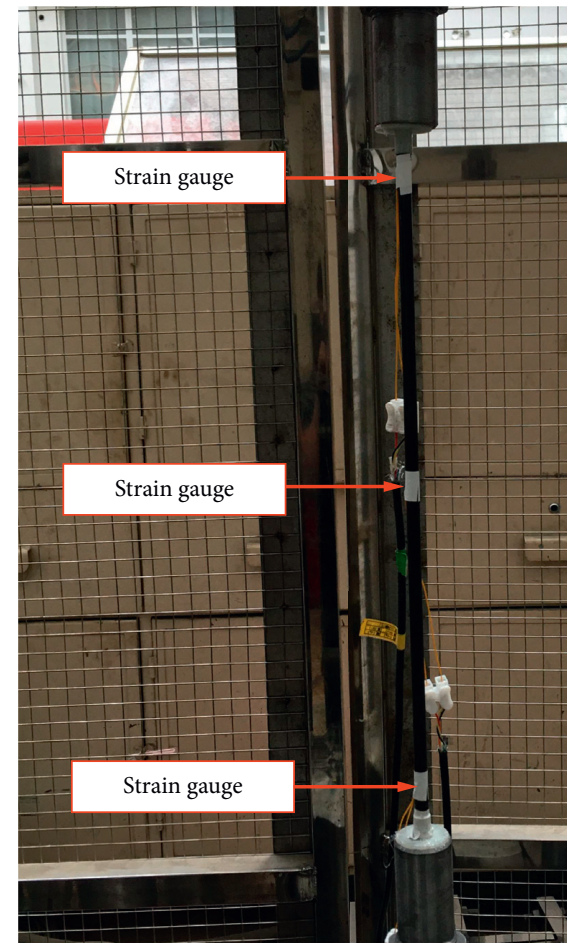

(b)

Figure 14: Static tensile test setup. 

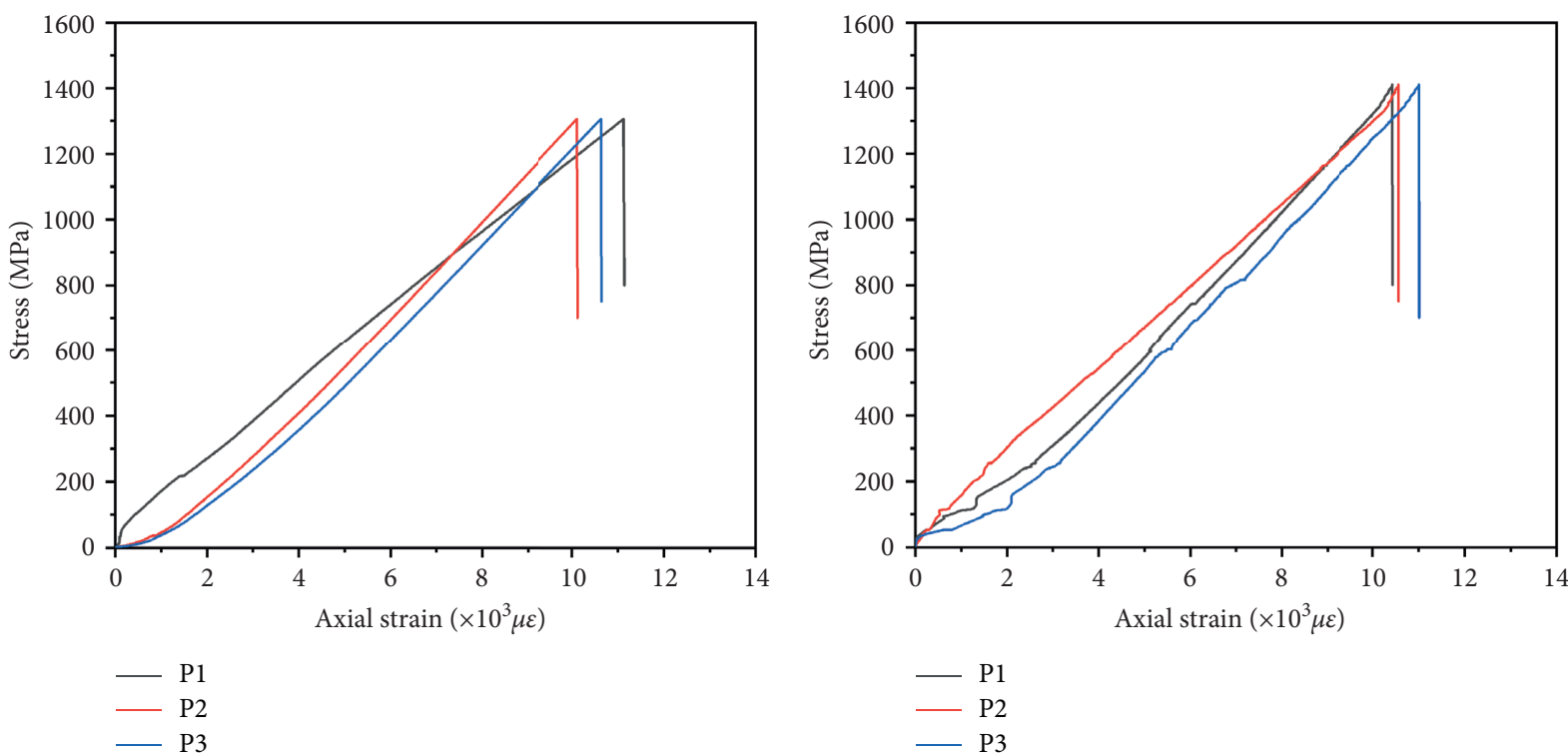

(a)
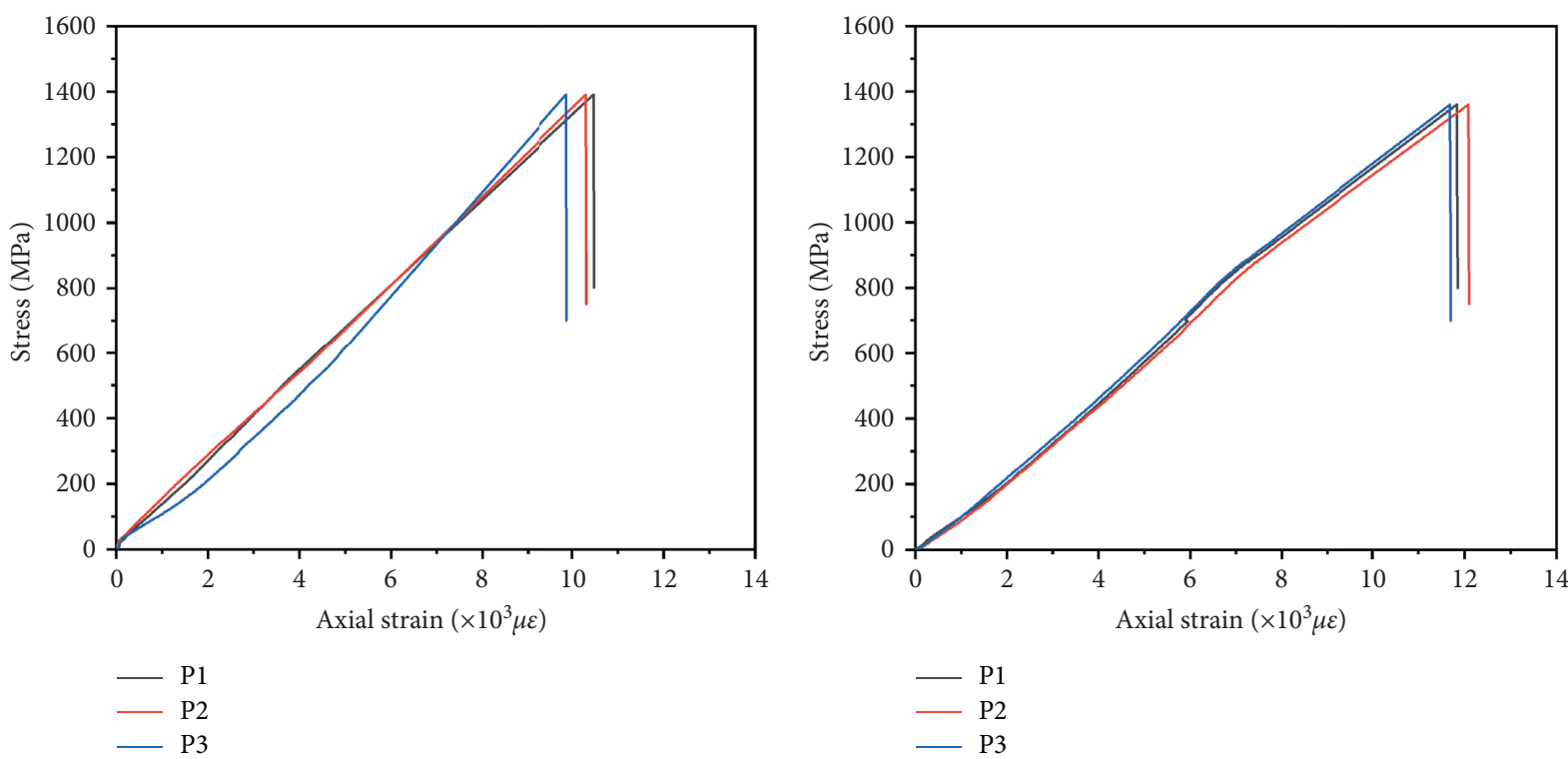

(c)

(d)

Figure 15: Continued. 


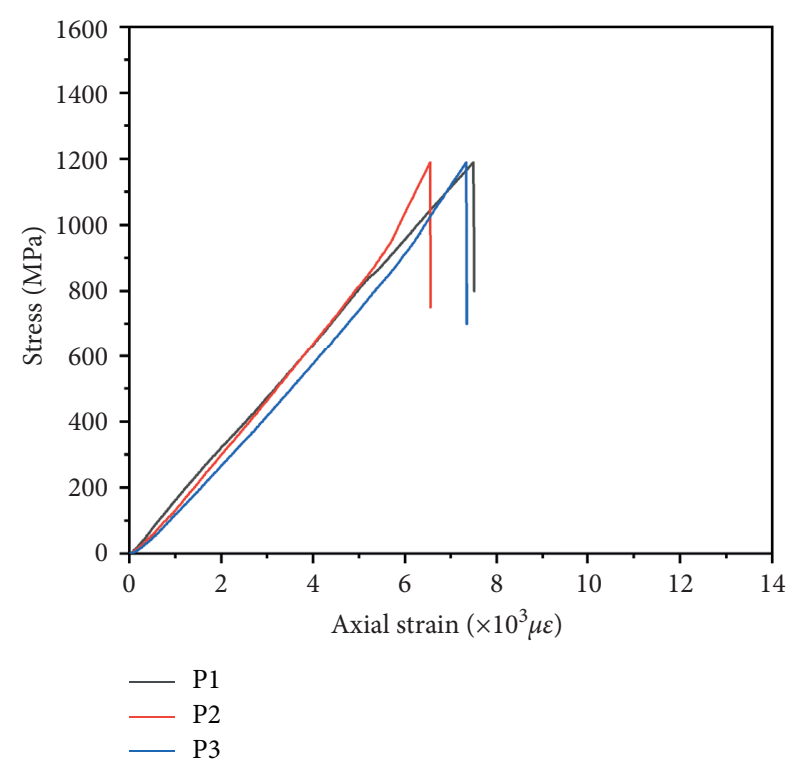

(e)

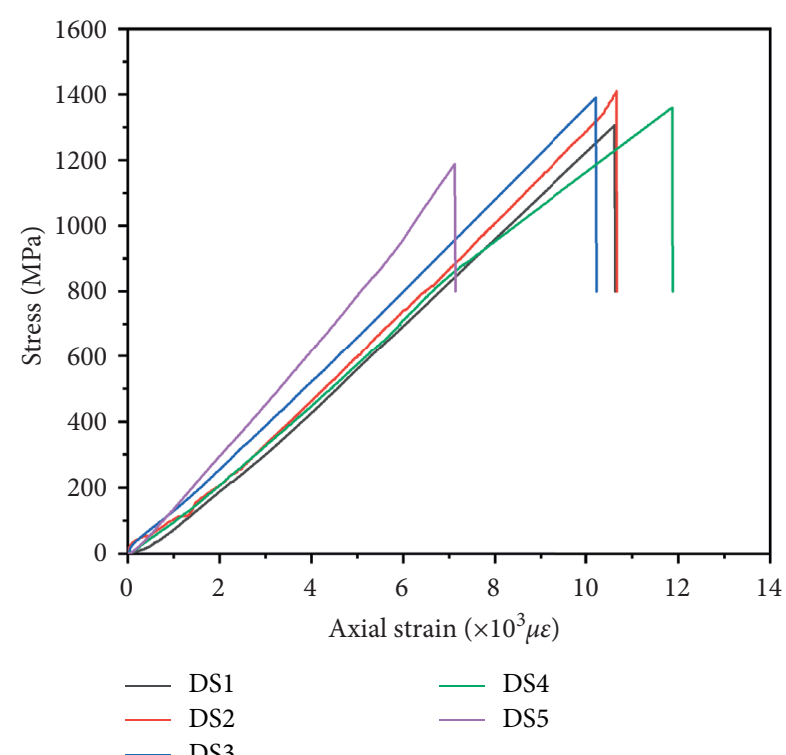

(f)

FIGURE 15: Stress-strain curves of CFRP rod anchored by dissolution-rebond anchor. (a) DS1. (b) DS2. (c) DS3. (d) DS4. (e) DS5. (f) Average.

TABLE 2: Ultimate tensile forces and stresses of CFRP rods anchored by dissolution-rebond anchors.

\begin{tabular}{|c|c|c|c|c|c|c|c|}
\hline Specimen number & DS1 & DS2 & DS3 & DS4 & DS5 & MV & $\mathrm{CV}$ \\
\hline Ultimate tensile force $(\mathrm{kN})$ & 65.6 & 70.9 & 69.9 & 68.4 & 59.7 & 66.9 & 0.067 \\
\hline Ultimate tensile stress $(\mathrm{MPa})$ & 1305.7 & 1411.0 & 1391.3 & 1361.5 & 1188.3 & 1331.4 & 0.067 \\
\hline
\end{tabular}

MV: mean value and CV: coefficient of variation.

anchorage efficiency of the dissolution-rebond anchor is $74 \%$.

4.3.2. CFRP Rod Anchored by the Traditional Bond Anchor. The stress-strain curves of five specimens are shown in Figure 17. The strain values were obtained from the strain gauges, and the stress values were calculated by the tensile force divided by the cross-sectional area (i.e., $50.24 \mathrm{~mm}^{2}$ ). Furthermore, each specimen has three stress-strain curves corresponding to the three strain gauges, and the average curves of the five specimens are fitted and compared in Figure 17(f).

It can be seen from Figure 17 that the stress-strain curves are approximately linear before the peak points, which indicates that the specimens mainly exhibited linear elasticity before failure. After the peak points, there are vertical line segments indicating the fact that the stresses dropped dramatically.

The ultimate tensile forces borne by the specimens and the corresponding ultimate tensile stresses are listed in Table 4 . As can be seen, the results are relatively uniform, and the average ultimate load and stress are $19.5 \mathrm{kN}$ and 388.1 MPa, respectively.

During the test, when the tensile load reached approximately $10 \mathrm{kN}$, the specimen of the traditional bond anchor made a slight click sound. Through visual observation, it was found that there was a very small amount of slip between the CFRP rod and the binder. With the load continuing, the sound of the specimen was getting clear. When the load reached the peak value, the specimen made a loud sound, and one end of the CFRP rod was pulled out from the bond anchor. The photos of the specimen after the failure are shown in Figure 18.

As can be seen from Figure 18, the failure mode of the CFRP rod anchored by traditional bond anchor is the typical slip failure. The failure was due to the debonding of the CFRP rod's surface and the binder. After the failure, both the CFRP rod and the binder were intact.

According to equation (4), the anchorage efficiency coefficients of the five specimens were calculated, and they are listed in Table 5 with their average value. As can be seen, the average anchorage efficiency of the tradition bond anchor is only $22 \%$.

4.4. Discussion. The average stress-strain curves of the CFRP rods anchored by dissolution-reond anchor and traditional bond anchor are shown in Figure 19.

As can be seen from Figure 19, both the ultimate tensile stress and strain of the specimen of dissolution-rebond anchor are significantly greater than that of the specimen of traditional bond anchor. The ultimate stress of the dissolution-rebond anchor is $1331.6 \mathrm{MPa}$, which is 3.4 times of 


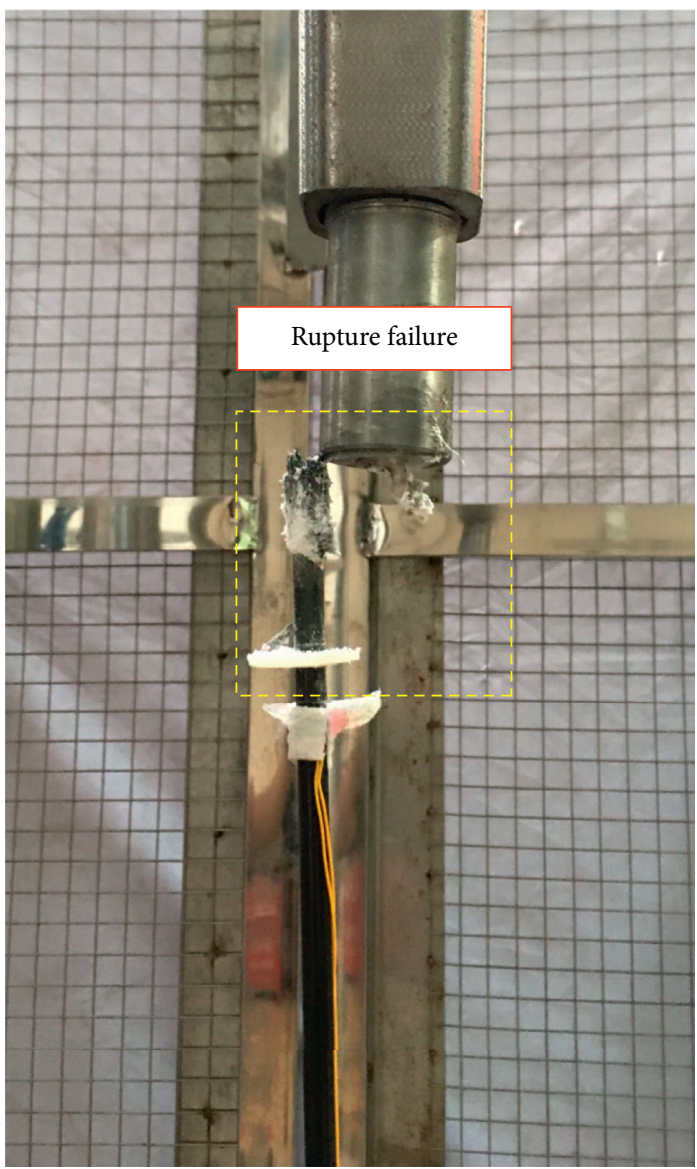

(a)

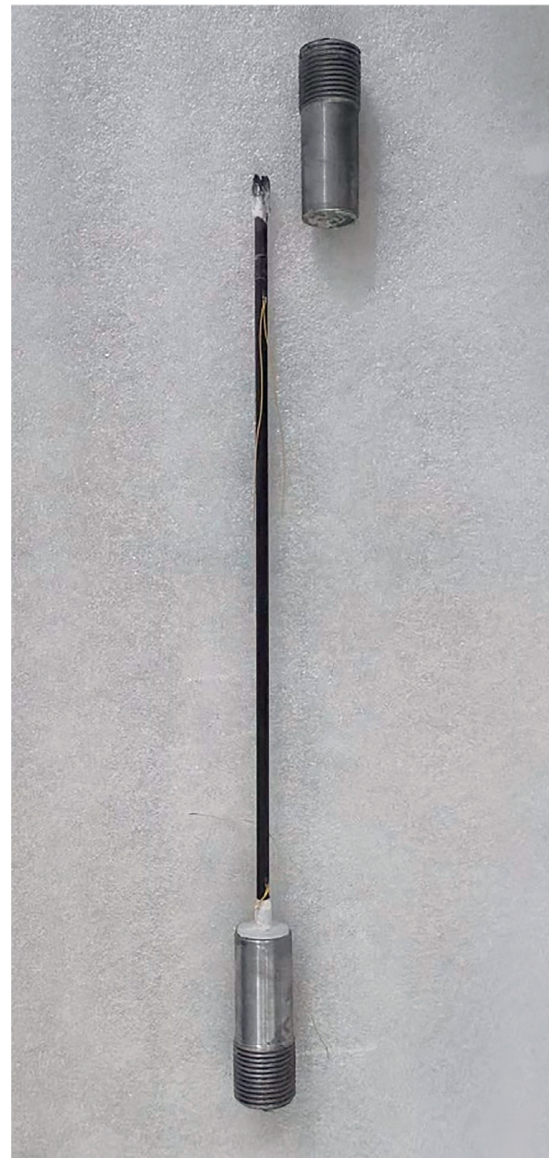

(b)

FIGURE 16: CFRP rod anchored by dissolution-rebond anchor after failure. (a) Specimen after failure. (b) CFRP rod after failure.

Table 3: Anchorage efficiency coefficient of the dissolution-rebond anchor.

\begin{tabular}{lccccccc}
\hline Specimen number & UDS1 & UDS2 & UDS3 & UDS4 & UDS5 & MV & CV \\
\hline$\eta_{a}$ & 0.73 & 0.78 & 0.77 & 0.76 & 0.66 & 0.74 & 0.067
\end{tabular}

MV: mean value and $\mathrm{CV}$ : coefficient of variation.
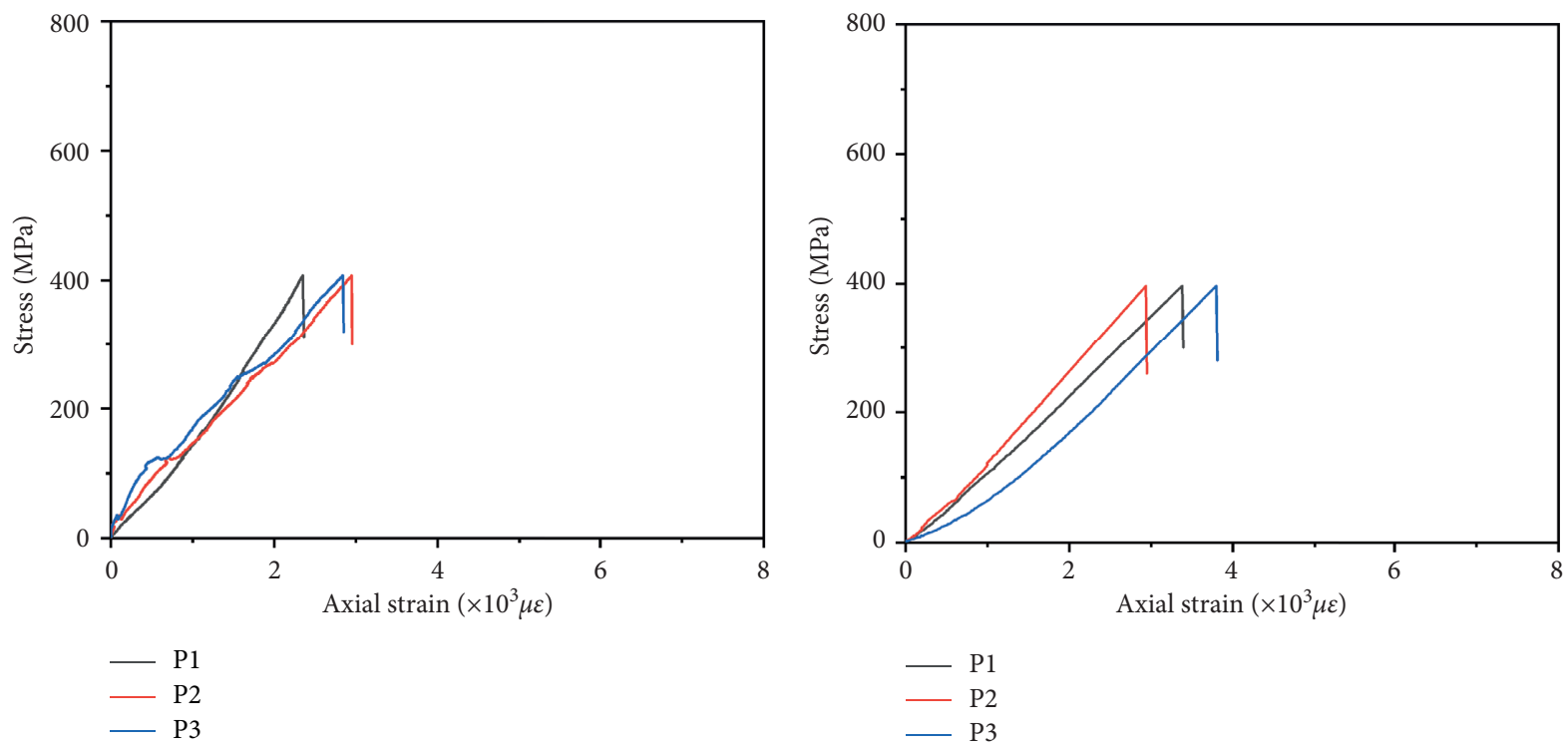

(a) 


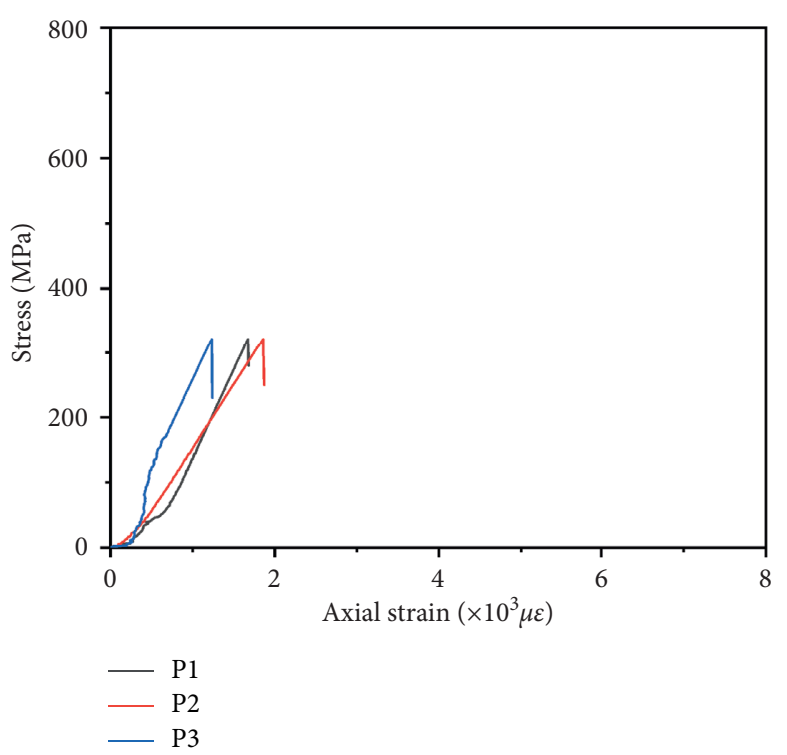

(c)

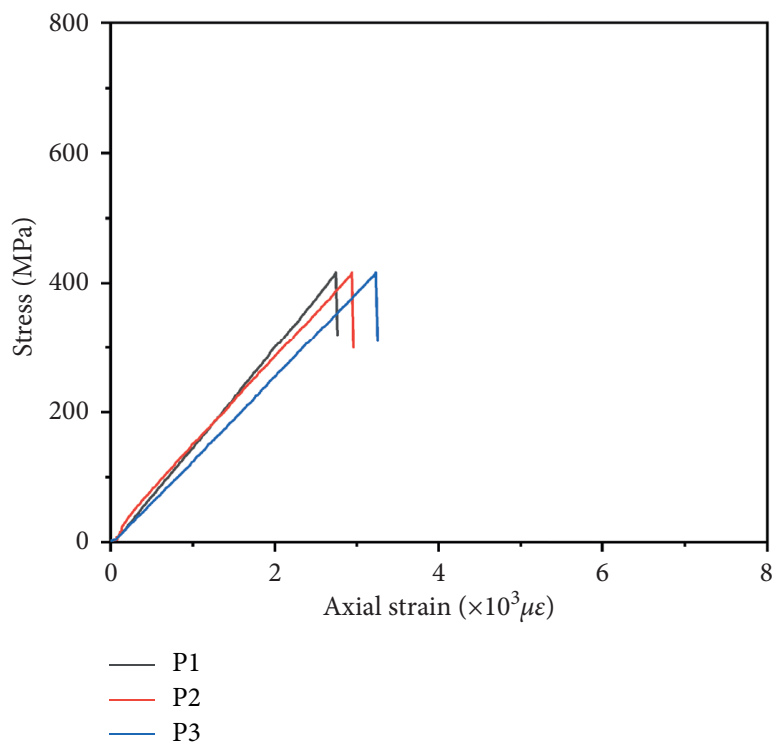

(e)

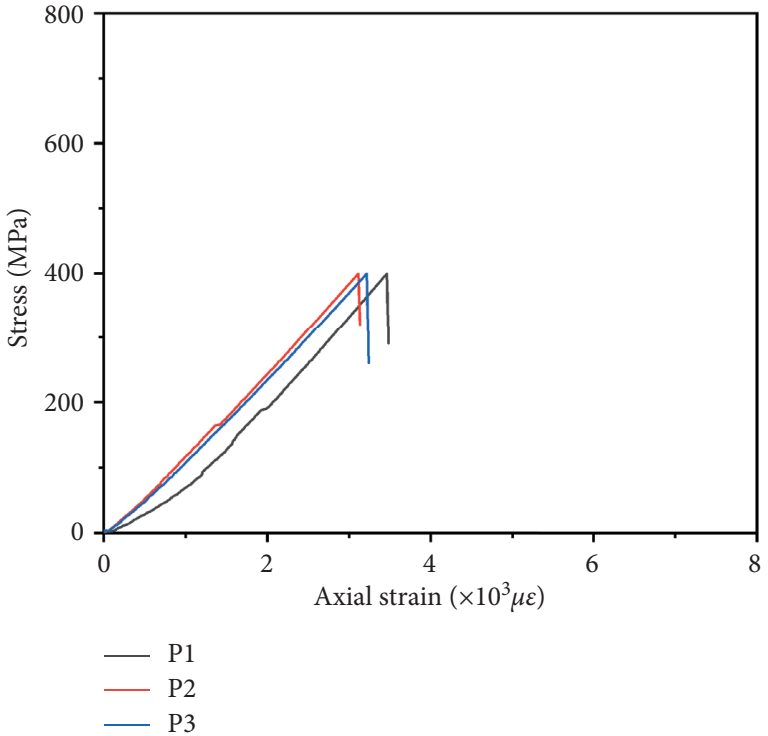

(d)

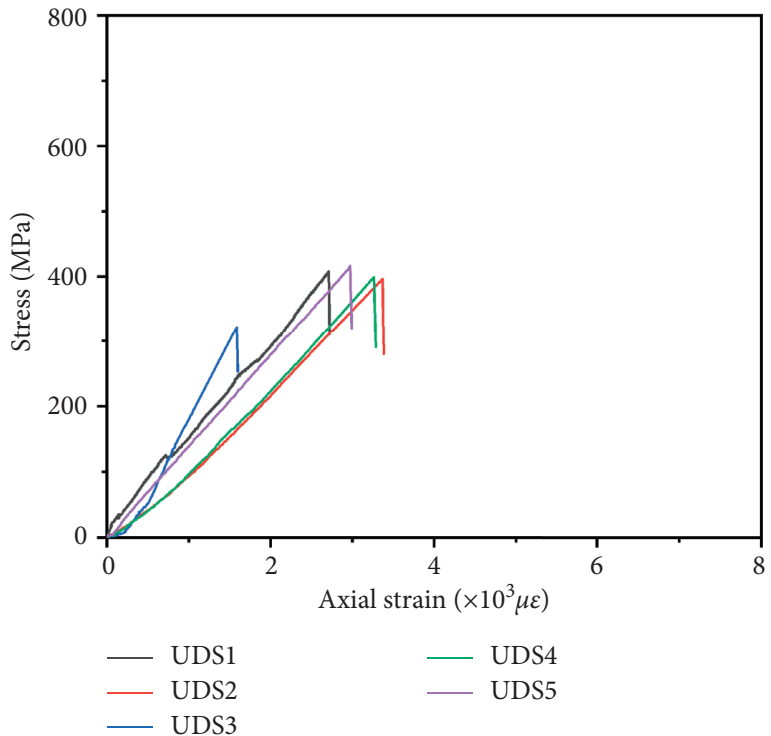

(f)

FIGURE 17: Stress-strain curves of CFRP rods anchored by traditional bond anchors. (a) UDS1. (b) UDS2. (c) UDS3. (d) UDS4. (e) UDS5. (f) Average.

TABLE 4: Ultimate tensile forces and stresses of CFRP rods anchored by traditional bond anchors.

\begin{tabular}{lccccccc}
\hline Specimen number & UDS1 & UDS2 & UDS3 & UDS4 & UDS5 & MV & CV \\
\hline Ultimate tensile force $(\mathrm{kN})$ & 20.5 & 19.9 & 16.2 & 20.1 & 20.9 & 19.5 & 0.098 \\
Ultimate tensile stress (MPa) & 407.3 & 396.5 & 321.4 & 399.2 & 416.1 & 388.1 & 0.098 \\
\hline
\end{tabular}

$\mathrm{MV}$ : mean value and $\mathrm{CV}$ : coefficient of variation.

the traditional bond anchor that is only $388.1 \mathrm{MPa}$. Furthermore, the slopes of the linear segments of two curves are similar, which indicates that the elastic moduli of two systems are very close and the dissolution-rebond will not decrease the stiffness of either FRP member or anchor.
The anchorage efficiency coefficients of dissolutionrebond anchor and traditional bond anchor are depicted and compared in Figure 20. As can be seen, the anchorage efficiency is considerably increased by dissolving and rebonding (from $22 \%$ to $74 \%$ ). 


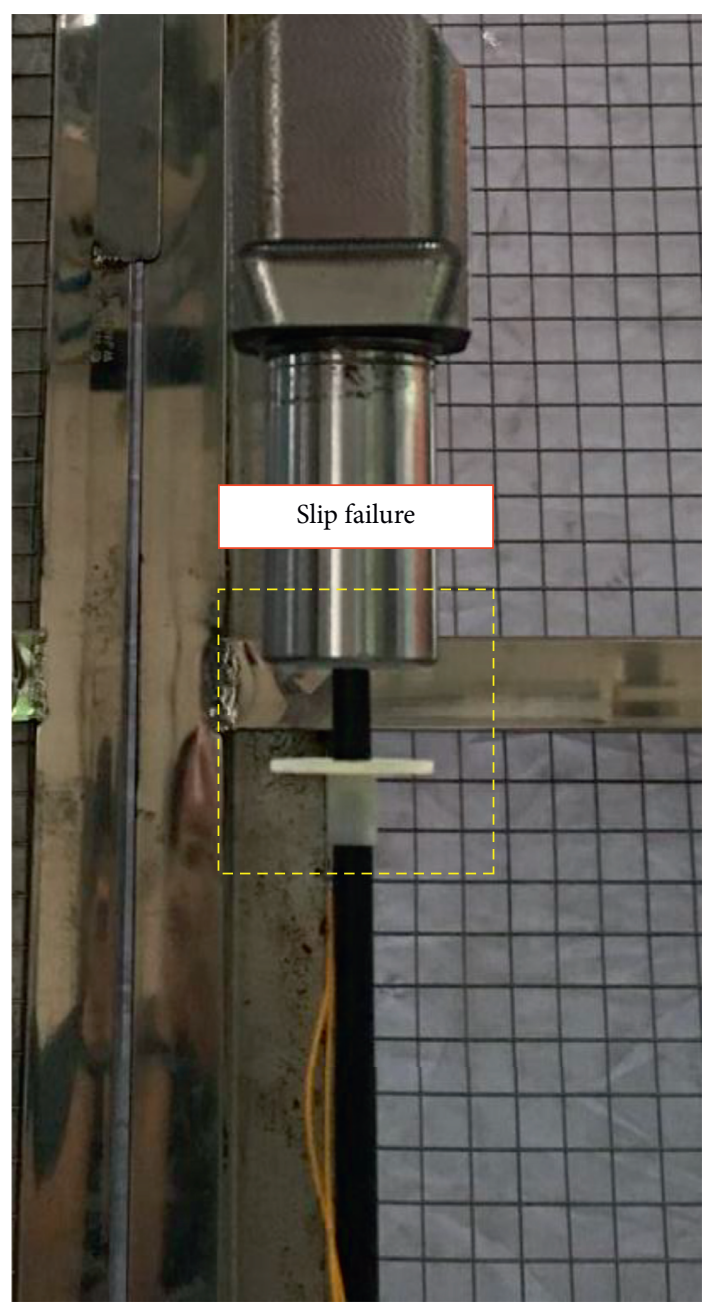

(a)

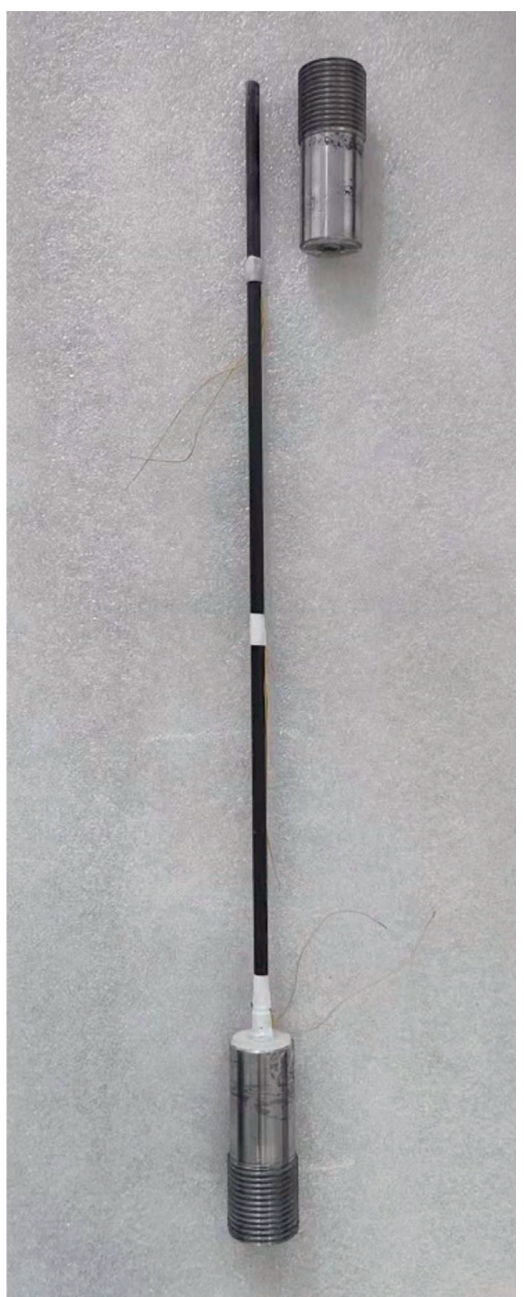

(b)

FIGURE 18: CFRP rod anchored by traditional bond anchor after failure. (a) Specimen after failure. (b) CFRP rod after failure.

TABle 5: Anchorage efficiency coefficient of traditional bond anchor.

\begin{tabular}{lccccccc}
\hline Specimen number & UDS1 & UDS2 & UDS3 & UDS4 & UDS5 & MV & CV \\
\hline$\eta_{a}$ & 0.23 & 0.22 & 0.18 & 0.22 & 0.23 & 0.22 & 0.097 \\
\hline
\end{tabular}

$\mathrm{MV}$ : mean value and $\mathrm{CV}$ : coefficient of variation.

Admittedly, the anchorage efficiency of the dissolutionrebond anchor cannot yet reach $100 \%$, because of initial defects including the breakage of fibers during manufacturing, voids between the fibers and the binder, and the damage of solvent to the fibers. However, increasing the anchorage length as well as eliminating the aforementioned 


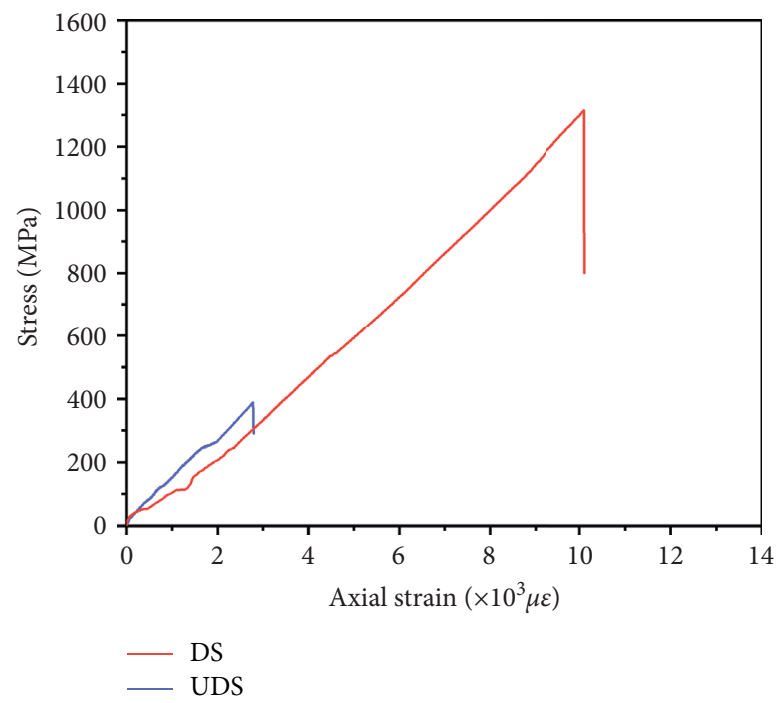

FIGURE 19: Average stress-strain curves of the CFRP rods anchored by dissolution-rebond anchor and traditional bond anchor.

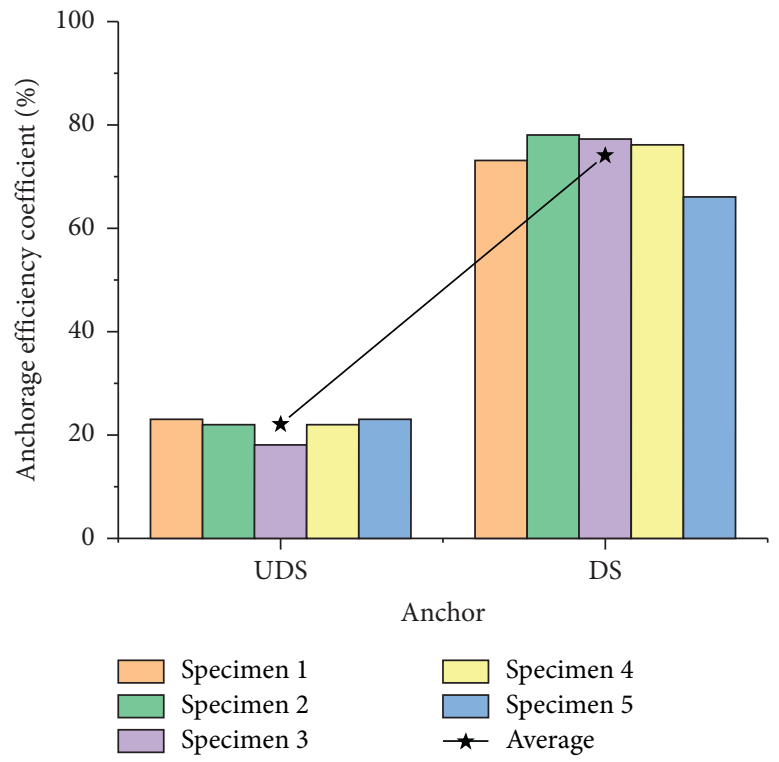

FIgURE 20: Comparison of anchorage efficiency between dissolution-rebond anchor and traditional bond anchor.

defects can help further increase the anchorage efficiency of the dissolution-rebond anchor and make it reach 100\% in the future.

\section{Conclusion}

In this paper, a novel bond anchor, namely, dissolutionrebond anchor, for unidirectional FRP member is proposed. The conceptual design and experimental investigation were performed. The following key conclusions can be drawn from this study:

(1) Through manufacturing the CFRP plain rod anchored by the dissolution-rebond anchor, the conceptual design of this novel bond anchor is proved to be feasible.
(2) Theoretically, the dissolution-rebond anchor is able to increase the bonding surface area and anchorage bearing capacity by $\left(D / D_{f}\right) V_{f}$ times compared with the traditional bond anchor, where $D$ is the FRP member diameter, $D_{f}$ is the fiber diameter, and $V_{f}$ is the fiber volume fraction. Because $D$ is much greater than $D_{f}$, the improvement of the bonding surface area and anchorage bearing capacity is very impressive.

(3) The static tensile test shows that the CFRP rod anchored by either the dissolution-rebond anchor or the traditional bond anchor has linear stress-strain relationship before failure. The failure mode of the dissolution-rebond anchor is the rupture of the fibers at the dissolved and undissolved transition sections, 
while that of the traditional bond anchor is the slip failure due to the debonding of the CFRP rod's surface and the binder. With the novel dissolutionrebond anchor, the ultimate tensile stress borne by the specimen and the anchorage efficiency are increased 3.4 times compared to the traditional bond anchor, and the anchoring stiffness remains basically unchanged.

(4) Due to the influence of the initial defects, there is a difference between the theoretical and experimental results, and the anchorage efficiency of the dissolution-rebond anchor in this paper has not yet reached $100 \%$. Eliminating the defects and increasing the anchorage length can narrow the gap between the theoretical and experimental values and further improve the anchorage efficiency.

\section{Data Availability}

The experimental data used to support the findings of this study are available from the corresponding author upon request.

\section{Conflicts of Interest}

The authors declare that there are no conflicts of interest regarding the publication of this paper.

\section{Authors' Contributions}

Yue Liu and Qing Wei conceived and designed the analysis. Yue Liu, Qing Wei, Ze-Yu Wang, and Peng Xiang performed the analysis and collected the data. Yue Liu, Qing Wei, ZeYu Wang, Long-Ji Du, and Bai-Yong Fu wrote the paper. Yue Liu, Qing Wei, Ze-Yu Wang, and Peng Xiang revised the paper.

\section{Acknowledgments}

This work was part of the project supported by the National Natural Science Foundation of China (NSFC) (no. 51908012), China Postdoctoral Science Foundation (2019M660962), and International Research Cooperation Seed Fund of Beijing University of Technology (2021B11). The financial support is gratefully acknowledged.

\section{References}

[1] S. Prashanth, K. Subbaya, K. Nithin, and S. Sachhidananda, "Fiber reinforced composites-a review," Journal of Material Science \& Engineering, vol. 6, no. 3, pp. 2-6, 2017.

[2] Y. Liu, T. Tafsirojjaman, A. U. R. Dogar, and A. Hückler, "Shrinkage behavior enhancement of infra-lightweight concrete through FRP grid reinforcement and development of their shrinkage prediction models," Construction and Building Materials, vol. 258, no. 2020, p. 119649, 2020.

[3] Y. Liu, Carbon Fibre Reinforced Polymer (CFRP) Cables for Orthogonally Loaded Cable Structures: Advantages and Feasibility, Logos Verlag, Berlin, Germany, 2015.
[4] Y. Liu, B. Zwingmann, and M. Schlaich, "Carbon fiber reinforced polymer for cable structures-A review," Polymers, vol. 7, no. 10, pp. 2078-2099, 2015.

[5] C. Sparks, I. Zivanovic, F. Sparks, J. Luyckx, S. Sparks, and W. Hudson, "Carbon fiber composite tendons for deepwater tension leg platforms," in Proceedings of the 2003 Offshore Technology Conference, Houston, TX, USA, May 2003.

[6] R. Geffroy, "The Laroin footbridge with carbon composite stay-cables," in Proceedings of the 2002 International Footbridge Conference, pp. 20-22, Paris, France, November 2002.

[7] H. Andrä and M. Maier, "Brückensanierung mit CFKLamellenspanngliedern", Faserverbundwerkstoffe - Innovationen im Bauwesen, Beiträge aus Praxis und Wissenschaft, pp. 65-76, Beuth Verlag, Berlin, Germany, 2005.

[8] S. L. Burtscher, "Wedge anchorage for CFRP strips," Journal of Composites for Construction, vol. 12, no. 4, pp. 446-453, 2008.

[9] V. Karbhari, Use of Composite Materials in Civil Infrastructure in Japan, WTEC report, International Technology Research Institute, World Technology (WTEC) Division, Baltimore, Maryland, 1998.

[10] U. Meier, H. Meier, and P. Kim, "Anchorage device for highperformance fiber composite cables," US Patent 5713169, 1998.

[11] U. Meier and H. Meier, "CFRP finds use in cable support for bridge," Modern Plastics, vol. 73, no. 4, pp. 87-91, 1996.

[12] Z. Lv and K. Mei, "First application of CFRP cables for a cablestayed bridge in China," Journal of Civil Engineering, vol. 40, no. 1, pp. 54-59, 2007.

[13] M. Schlaich, B. Zwingmann, Y. Liu, and R. Goller, "Zugelemente aus CFK und ihre Verankerungen," Bautechnik, vol. 89, no. 12, pp. 841-850, 2012.

[14] J. W. Schmidt, A. Bennitz, B. Täljsten, P. Goltermann, and H. Pedersen, "Mechanical anchorage of FRP tendons - a literature review," Construction and Building Materials, vol. 32, no. 2012, pp. 110-121, 2012.

[15] Standardization Administration of China, Anchorage, Grip and Coupler for Prestressing Tendons (GB/T 14370-2015), Standards Press of China, Beijing, China, 2015.

[16] D. Chung, Carbon Materials: Science and Applications, World Scientific Publishing, Singapore, 2019.

[17] X. Yi, S. Du, and L. Zhang, Composite Materials Engineering, Vol. 1, Springer, Berlin, Germany, 2018.

[18] T. Wu, W. Zhang, X. Jin, X. Liang, G. Sui, and X. Yang, "Efficient reclamation of carbon fibers from epoxy composite waste through catalytic pyrolysis in molten $\mathrm{ZnCl} 2$," $\mathrm{RSC}$ Advances, vol. 9, no. 1, pp. 377-388, 2019.

[19] H. Luo, W. Wang, and X. He, Adhesives for Building Structures and Their Construction Technology, Chemical Industry Press, Beijing, China, 2nd edition, 2016.

[20] S. Zhang, Steel Material Manual: Carbon Structural Steel, Standards Press of China, Beijing, China, 2010.

[21] Standardization Administration of China, Test Method for Basic Mechanical Properties of Fiber Reinforced Polymer Bar (GB/T 30022-2013), Standards Press of China, Beijing, China, 2013.

[22] Y. Zhu, L. Liu, J. Zhang, W. Zhu, H. Wang, and Z. Zhou, "Numerical simulation and failure analysis of cfrp bar bonded anchorage system," Acta Materiae Compositae Sinica, vol. 32, no. 5, pp. 1414-1419, 2015.

[23] MTS Systems Corporation, MTS Insight ${ }^{\mathrm{TM}}$ Material Testing Systems User Manual, MTS Systems Corporation, Eden Prairie, Minnesota, 2020. 